\title{
SocArXiv
}

Preprint : November 5, 2018

10.31219/osf.io/dz9xr

\section{Designing Has No Given Problems, No Given Processes, and No Given Solutions}

\author{
Jordan Beck \\ Pennsylvania State University
}

\author{
Erik Stolterman Bergqvist \\ Indiana University Bloomington
}

\begin{abstract}
The question of what makes design unique is explored. We argue that a scientific lens can be used to reveal distinguishing characteristics of designing. We apply Karl Popper's criteria of falsifiability, refutability, or testability to four design process theories: Bounded Rationality, FBS Framework, Figural Complexity, and C-K Theory. Our ambition is to demonstrate that (1) some theories about design can be construed as scientific in Popper's terms, and that (2) these theories do not frame design as a systematic, objective, and rational process. Instead, they frame designing as an approach distinct from science in that it has no given problem, no given process, and no given solution.
\end{abstract}

Keywords: design activity, design process, design theory, philosophy of design, framing.

\section{Introduction}

Design research has been grappling with an ontological dilemma, which Karl Popper described for science as the "problem of demarcation"(Popper 2002b). The dilemma can be translated for design as a set of questions: What makes designing what it is? What is its nature and core? Can that core be theorized? Popper was interested in similar questions for science, and he generated answers in the form of criteria that could be used to distinguish scientific theories from other kinds.

There have been attempts to develop similar criteria for design theory. In some cases, these attempts have seemingly tried to modify Popper's approach (Jones and Gregor 2007). Other attempts start with what they see as the core of design. They argue that theories about design should not only describe design but also incorporate and manifest its unique characteristics (Chakrabarti and Blessing 2014; Hatchuel et al. 2011). This sort of theorizing makes sense if a key aspect of the agenda of design research is to understand and study designing on its own terms within its own culture (Cross 2001; Nelson and Stolterman 2012). But studying design 
in this way should not mean that we give up in our attempts to understand design from other perspectives, such as that of science.

There are many ways to articulate the fundamental nature of designing, each of which is dependent on why it is done in the first place. For example, if researchers want to support design practitioners then their approach, and the outcome of their work, will be different than if they were working purely because they want to define an ontology of designing. In our work, we wish to examine the possibility of theories about designing that (1) answer to scientific criteria while (2) respecting the unique nature of designing.

This paper engages in an analysis of four design process theories in . It asks, Can there be scientific theories of designing that do not also scientize designing? By "scientize" designing, we mean a theory that explains or describes designing as a form or version of scientific activity, i.e. as an "organized, [objective,] rational, and wholly systematic approach [to designing]..." (Cross 2001). We do not mean to imply that explaining and describing designing as a form of scientific activity is necessarily bad. But our interest is in attaining a deeper understanding of design as an activity distinct from scientific activity.

There is no agreed upon framing of scientific activity (Hatchuel et al. 2013) or of scientific theories. Popper's account of science has been criticized (Kuhn 1970, e.g.), and alternative perspectives have been put forth. We will discuss some of these accounts in more depth in a subsequent section. Similarly, there is no agreed-upon understanding of design and design theories. This is to be expected (Galle 2011), and it means that as researchers we intentionally choose ways to frame and discuss science and design.

When we discuss science and designing in this text, we therefore see these concepts as exemplifying what Max Weber calls ideal types, which "never seek to claim validity in terms of reproduction of or correspondence with reality" (Kim 2017). Weber proposed ideal types as a methodology in which a construct such as science or design is framed in a useful way for analysis. The ideal type methodology has been used in texts comparing design and science (Farrell and Hooker 2012; Galle and Kroes 2014) where it enables researchers to (1) describe ways in which design and science are supposed to be practiced and (2) foreground and account for their own values as researchers in a community.

So, although we discuss science and design as if there is a "given" and natural existence of these activities, we do not argue for correspondence between our chosen theories of designing and reality. Nor do we suggest that science, as we present it, is science as practiced. Rather, we frame it as science as it is supposed to be practiced, which is "the stereotype of science that idealizes its every aspect," (Ziman 2000) including the precision and objectivity of its methods. The legend of science is itself an ideal type that could be said to capture what many consider to be a universal and correct understanding of science.

It is clear that theory development and empirical experimentation, both of which can be interpreted as scientific, undermine any attempt to argue for ' $a$ ' universal and correct understanding of scientific activity. Theory development and empirical experimentation can both be understood as scientific activity, which means that there are at least two ways of understanding it. And each of these ways probably has some nuance. For instance, there are a few possible ways of understanding empirical experimentation (e.g. from Popper's or Kuhn's perspective). So, while there might be a clear ontology for understanding scientific activity, there is not one universal and correct understanding. Our decision to discuss scientific activity and designing as "given" and naturally occurring should therefore be seen as a consequence of 
our intention to keep the investigation focused and not as an argument for "one true science" or "one true design."

Our work rests on the assumption that there can be scientific theories of design that do not "scientize" design and that a scientific lens can potentially reveal important aspects of designing that may be less visible if designing is understood through a designerly lens. This assumption rests in turn on the idea that a scientific lens and a designerly lens have distinct purposes. While a scientific lens is used to reveal the 'true' nature of designing, a designerly lens may be used to create 'useful' understandings of designing.

There are many theoretical accounts of designing (Dubberly 2018; Lawson and Dorst 2009). Most of these theories are designerly in nature in the sense that they are theories that have been designed to be useful to designers rather than scientifically "correct" and verifiable (or falsifiable). In most cases, these theories make claims about being useful but do not make scientific claims. This is all good and well, but we suggest that in addition to these designerly accounts of designing there are also theories that make stronger knowledge claims by providing a scientific account of designing. We do not see designerly theories of designing as less valuable or interesting, but in this work they are not our primary objects of study.

To investigate our assumptions, we apply Karl Popper's criteria for the scientific status of a theory to four seminal theories of designing: Bounded Rationality (Simon 1996), the FBS framework (Gero and Kannengeisser 2014), Figural Complexity (Schön 1990), and C-K Theory (Hatchuel and Weil 2003, 2009). Popper's criteria can be summarized with the concept of falsifiability, which means that a theory is scientific only if it can be disproved.

We are interested in assessing whether a theory about designing could be deemed scientific in nature while still respecting the integrity of designing. Consequently, we do not ask whether these theories are also 'valid' or 'interesting' (Davis 1971; Weick 1989), which would be important questions for assessing scientific utility. We also do not discuss issues of rigor, relevance, or practical applicability-all of which are potentially important when it comes to evaluating theories. One can and should expect more from a scientific theory than falsifiability. However, these expectations are beyond the scope of this paper. Through our analysis we aim to demonstrate that (1) Bounded Rationality, the FBS framework, Figural Complexity, and CK theory can be construed as scientific in Popper's terms, and (2) they do not scientize the design process.

We organize the paper as follows. First, we summarize four classic theories of designing: CK Theory, FBS Framework, Figural Complexity, and Bounded Rationality. These descriptions are brief - not comprehensive. Next, we discuss the problem of distinguishing scientific theories from other kinds. Karl Popper called this the problem of demarcation, and he proposed a set of criteria that could be used to distinguish scientific theories from other kinds. On the basis of Popper's work, we synthesize a framework for analyzing theories to determine whether they are scientific. And we apply this framework to CK theory, FBS Framework, Figural Complexity, and Bounded Rationality. Then we argue that-excepting Bounded Rationality-these theories do not scientize designing. They do not frame design as a systematic, objective, and rational process. We argue that they frame design as an activity with no given problem, no given process, and no given solution; qualities that distinguish designing from scientific activity. Finally, we end with a discussion about the offerings and potential implications of scientific theories about designing. 


\section{Design Process Theories}

The focus of our investigation is designing, which means we foreground the processâĂ $\breve{T r a t h e r}$ than its outcomes-as the primary object of inquiry even though the relationship between the designed artifact and the process of designing is important. It is also the case that the understanding of designing we investigate does not cover all aspects of designing that could potentially be theorized. Consequently, from some perspectives and in certain respects the theories we analyse can be seen as incomplete. Our perspective emphasizes designing as a pragmatic approach that is primarily about how ideas are transformed into artefact proposals. But designing can also be theorized as a process embedded in society with emphasis on historical, economical, aesthetic, or technological aspects (Cavalluci 2014; Margolin 2014; Taura 2014; Xenakis and Arnellos 2013).

Our search for theories of designing led us to several notable, recent contributions in the field of design research (Chakrabarti and Blessing 2014; Hatchuel et al. 2011). Chakrabarti and Blessing have edited a comprehensive anthology of the state of theory in design. A key insight in their introductory chapter is that design research does not yet have a means to "test and refute" theories, which at least assumes that the theories in question are testable and subject to refutation, that is, that they are scientific. One of our goals is to examine this assumption. In addition, Hatchuel et al. have conducted a systematic analysis of four "formal" design theories partly in order to develop a set of Popperian-style demarcating criteria for design theories (Hatchuel et al. 2011). In our work, we aim to apply Popper's criteria for scientific theories and not to synthesize criteria for design theories.

This is a key distinction between our approach and that of Hatchuel et al. Their analysis yields the insight that "generativeness" and "robustness" are demarcating features of design theories. Our goal is not to challenge their results. It is to provide a scientific perspective from which to evaluate and understand design theories and to suggest that this perspective has important consequences for design.

Ultimately, we selected four theories to analyze, including: (1) C-K Theory, (2) FBS framework, (3) Figural Complexity, and (4) Bounded Rationality. We will describe each theory below. However, since each theory is well developed, it is impossible to make fair descriptions in a few paragraphs. Our descriptions should therefore be seen as indications of what the theory is like as a way for the reader to understand our work and not as comprehensive descriptions.

- Hatchuel and Weil propose C-K Theory in response to what they deemed a lack of design theories accounting for the generation of novel concepts. Their theory describes designing as an interaction between two interdependent spaces: a concept space (Cspace) and a knowledge space (K-space). According to this theory, designing starts with concept generation. The C-space is filled with partly unknown design concepts. "Partly unknown" describes the incomplete knowledge a designer possesses about concepts in the C-space. We can think of concepts as logical propositions that are neither true nor false. To prove or disprove these propositions, designers venture into the $\mathrm{K}$-space to test them. The output of activity in the $\mathrm{K}$-space is knowledge, which designers take into the C-space. Newly generated knowledge may result in abandoning a concept (if it is shown to be "false" by the K-space), partitioning and iterating on a concept (if it remains unknown even after working in the K-space), or earmarking a concept as a potential design candidate (if it is shown to be true in the K-space). There are no 
time constraints put on the interaction between the $\mathrm{C}$ and $\mathrm{K}$ spaces. Nor are there any strictly prescribed methods of "concepting" or "knowledge-generating."

- The FBS framework is derivative of the FBS ontology, which describes designed artifacts in terms of what they are for (function), what they do (behavior), and what they are made of (structure). The FBS framework builds on the ontology to explain designing as the iterative transformation of functions, behaviours, and structures. Gero and Kannengiesser describe the iterative transformation from functions to behavior and from behavior to structure as the most basic view of designing. The FBS framework describes eight fundamental transformations constitutive of any discipline-agnostic design process: formulation, synthesis, analysis, evaluation, documentation, reformulation type 1(RT1), reformulation type 2 (RT2), and reformulation type 3 (RT3). For an in-depth description of these transformations (Gero and Kannengeisser 2014). As with $\mathrm{C}-\mathrm{K}$ theory, the authors do not prescribe concrete processes or methods of transforming functions, behaviours, or structures. The FBS framework has been covered in the following texts (Cascini et al. 2013; Gero 1998; Gero and Kannengeisser 2003; Vermaas and Dorst 2007).

- In his essay The Design Process, Donald Schön introduces the notion of figural complexity with the simple metaphor of changing one's diet (Schön 1990). Schön describes diets as complex things, but their complexity is what he describes as combinatorial. This means that removing or adding elements to a diet changes it only to the extent that there is newly added or removed element. The change does not affect the other elements of the diet nor does it affect the diet as a whole. Figural Complexity is different in the sense that the addition or subtraction of element(s) to a figurally complex entity does affect other elements such that the entity must be considered differently as a whole. As a theory about designing, figural complexity describes the complex interaction between the designer and (1) design proposals and (2) design situations and structures over time. Designers are constantly learning things that cause changes to design situations, structures, representations, and design proposals. They must therefore develop the competence to "manage complexity" (Schön 1983). Changes in one area necessitate changes in others. The theory of figural complexity has serious logical implications for the nature of, and relationships between, design problems, design solutions and the design process that, according to Schön, are unique to designing and distinct from scientific rational processes.

- Bounded Rationality (Simon 1996) refers to Herbert Simon's conception of the design process as a special case of problem solving. There are two aspects of bounded rationality that are especially important and serve to distinguish it from the other theories. (1) The understanding of the initial design problem remains unchanged throughout the process, and (2) the process itself entails a series of decisions made by selecting "satisficing" items from finite lists of requirements, functions, behaviors, structural elements, and the like. A designer would be responsible for generating and selecting the satisficing items from this list through a rational, analytical process. Bounded rationality can be illustrated using a common leisure activity, such as going to see a film (Hatchuel 2001). When planning to see a film, a group may use certain decision-making heuristics, such as: search strategies (e.g. which movies are playing and where), knowing strategies (e.g. what do film critics have to say about the different options), satisficing criteria (e.g. 
the definition of a 'good' movie), and logics of discovery or exploration (e.g. choosing a film based on award nominations or the newness of its actors). The outcome of these processes is a decision about which film to see and where to see it. It is a direct response to the original "problem," which remained unchanged throughout the process. Bounded rationality theorizes designing as a process of exploring a finite solution space and, through rational decision-making heuristics, arriving at a satisficing solution.

We argue that each of these theories claims to say something about the true nature of designing. However, to make such a claim does not in and of itself imply scientificness. Freud claimed to say something about the true nature of the mind, but according to Popper, Freud's theory was pseudo-science at best and the stuff of myth at worst. Since we cannot take the word of the theorist as a sign of scientificness, we have to find a way to assess it independent of the theorist's claims. So, our task is to see if it is possible to make the case that C-K theory, the FBS framework, Figural Complexity, and Bounded Rationality can be understood as scientific in Popper's terms.

\section{The Problem of Demarcation in Science and Design}

The philosophy of science is a broad field that asks questions about the nature of science. These questions address the nature of scientific activity, scientific knowledge, and even the place of scientific knowledge in society. In his text Theory and Reality, Peter Godfrey-Smith glosses of some of the central questions in the field, which include "what science is, how it works, and what makes science different from other ways of investigating the world" (GodfreySmith 2009). There are nuances to each of these questions. For instance, one approach to distinguish science from other ways of investigating the world is in terms of its theories. Karl Popper grappled with this issue, which he described as "the problem of demarcation."

He was struggling with questions such as: What distinguishes science from other approaches? What distinguishes scientific theories from other types? The latter question is highly relevant in design research, where scholars engage in theorizing partly as a means of establishing disciplinary boundaries. In parallel with Popper's question about science we can ask: What is design? What distinguishes design theories from other kinds?

In his famous book, Conjectures and Refutations: The Growth of Scientific Knowledge, Popper summarized the demarcation criteria for a scientific theory with the terms "falsifiability, refutability, or testability" (Popper 2002b). These terms capture the essential qualities of a scientific theory, which are, in Popper's view, qualities that non-scientific and pseudo-scientific theories lack. Popper pointed to Freud's theory of psychoanalysis, Marx's theory of history, and Alfred Adler's theory of individual psychology as examples of non-scientific theories. $\mathrm{He}$ was frustrated by the fact that proponents of these theories only ever found confirming evidence out in the world. Observations always seemed to verify the theories. Nothing seemed to contradict them or undermine their explanatory power. These theories were according to Popper unfalsifiable and, thus, non-scientific. As a counterpoint, he held up Einstein's theory of relativity as an exemplar scientific theory.

Popper stated that, from Einstein's theory one could deduce that stars near the sun would appear to have moved away from the sun and each other. Such a deduction is risky in the sense that it is "incompatible with certain possible [empirical] results-in fact [it is incompatible] with results that everyone before Einstein would have expected" (Popper, 1963). Einstein's theory 
and its predictions diverge from well-established scientific theory, and the consequences, if correct, would be profound. Popper also argued that Einstein's theory is falsifiable both logically and empirically, that is, both when it came to its practical, empirical predictions as well as its internal logical consistency.

Popper's work on falsification as a demarcation criterion of scientific theory has since then been critiqued and developed by others (Kuhn 1970; Lakatos 1970). In one of the most notable critiques, Thomas Kuhn, while acknowledging that Popper is not a naive falsificationist, suggested that Popper could be treated as one. Kuhn's claim for treating Popper as a naive falsificationist rests on two grounds: (1) there is no such thing as conclusive disproof of a theory and (2) because of (1) only logical falsification is left as the demarcating criterion of a scientific theory. If there is no such thing as conclusive disproof, can we treat Popper as a naive falsificationist? And what might this mean for the validity of his criterion as an analytical framework?

We know that Popper agreed to the impossibility of conclusive disproof. In Logic of Discovery he wrote, "In point of fact, no conclusive disproof of a theory can ever be produced" (Popper 2002a). This has to do with what he described elsewhere as the problems of the 'empirical basis,' which could include unreliable research design and/or errors of observation. Such problems challenge the integrity of results that would otherwise seem to falsify a theory. As powerful as science might be, its practices and procedures remain subject to human error. But acknowledging the lack of conclusive disproof does not establish Popper as a naive falsificationist nor do we believe it merits his treatment as one.

In the absence of conclusive disproof, we have more than just logical falsification as the demarcating criterion of scientific theories. We also have the 'empirical basis.' Hence, we suggest that the empirical basis is a useful and valid tool for determining the scientificness of a particular theory about designing.

In the discourse on falsification several new concepts have been developed. For instance, a nuanced distinction was made between naive falsificationism, methodological falsificationism, and sophisticated falsificationism (Lakatos 1970). Even though these more precise definitions of falsification are important, what matters for our purposes is whether these different kinds of falsificationism imply different demarcation criteria for the scientific status of a theory.

It is clear that naive and methodological falsification differ in some ways more than others in their demarcation criteria, but in our view, their perspective on the falsifiability of a theory adheres to a common core. A theory may be "admitted" as scientific if it is falsifiable. To be falsifiable means that a theory is capable of producing basic statements, which are "statements asserting that an observable event is occurring in a certain individual region of space and time" (Popper 2002a). These could be basic statements that are incompatible with preexisting ones or basic statements about a new phenomenon. An example of a basic statement would be the proposition that, during the day, stars close to the sun would look as though they had moved away from the sun and from each other. This is an observable event occurring in a certain individual region of space and time. And it was incompatible with other, preexisting basic statements that could be derived from Newtonian theories.

Methodological falsification and naive falsificationism diverge in their treatment of falsification. Falsification is the process of falsifying a theory whereas falsifiability refers to the quality of being falsifiable. Since we are concerned in this paper with whether or not a theory can be understood or accepted as scientific we only concern ourselves with falsifiability, not fal- 
sification, and so a deeper analysis of the differences of these kinds of falsification would be excessive at this time.

\section{4. Analysis of Four Design Process Theories}

One way to analyse our four theories in terms of falsifiability is by considering each one in light of those theories that Popper described as non-scientific (e.g. Freudian psychoanalytic theories or Marxist theories of history). Our point of departure can be a question asked by Popper, but revised for our current purposes: What makes Marx's theory of history or Freud's theory of psychoanalysis different from our chosen theories of designing? Think of a proposition as simple as "all men are mortal." It is unfalsifiable since, as with Marx and Freud's theories, everywhere we look we can only find confirming evidence of its truth. No factual propositions exist that clash with it. We define factual propositions as those propositions with high truth-values, where truth-values are functions of empirical observations and mutual consensus within a community. Newtonian mechanics, for instance, had centuries of empiricism and consensus within the scientific community. And so, when Einstein proposed his theory of relativity, it clashed with established, antithetical factual propositions about the way the world worked. In addition, unlike Marx and Freud's theories, Einstein's could be falsified by empirical observation. This means that it was capable of producing basic statements, which must be "testable, inter-subjectively, by "observation"' (Popper, [1959] 2002). Since we are concerned with evaluating the falsifiability of a theory, we must attempt to deduce basic statements from each theory. So, the question becomes: What basic statements about designing are possible to extract from C-K theory, the FBS framework, Figural Complexity, and Bounded Rationality?

$\mathrm{C}-\mathrm{K}$ theory describes designing as an expansion of two conceptual spaces: concept space (C) and knowledge space $(\mathrm{K})$. This expansion is accomplished through movement back and forth between the two spaces. Since (C) and (K) are conceptual spaces we cannot empirically observe them when we observe the process of designing. However, in their discussion of axioms for defining and partitioning C-sets, Hatchuel and Weil provide us with insights that could translate into empirically viable factual propositions about designing. For instance, they write that concepts in space (C) do not have "operational" or "stable" definitions (Hatchuel and Weil 2009). This means that (1) concepts in the C-space cannot be defined in terms of any processes used to create or iterate upon them and that (2) the definition of a concept is always subject to change. An important aspect of an operational definition is the 'replicability' of the procedure used to define a concept. But since concepts have no operational definitions there is (by definition) no replicable procedure that could be used to create or iterate upon them. We could formulate the following basic statement about designing: Initial concepts transform after designers generate new knowledge in the K-space.

Basic statements about designing might look different if we turn to the FBS framework. Gero and Kannengiesser describe designing as a process of transformations between functions, behaviors, and structures. Moreover, they outline a list of eight transformations that begin to describe any profession-independent design process (Gero and Kannengeisser 2014). In other words, engineering, architecture, fashion, and software design processes, among others, can be described in terms of this list of transformations. We suggest that these transformations can also be used to generate basic statements about designing, which can form the basis of empirical studies. In fact, the FBS framework has been validated empirically through 
the use of verbal protocol analysis. And these 'validations' are presumably the results of developing and testing basic statements about designing, such as: architects spend more time thinking about "functions" than software designers and mechanical engineers Kan and Gero (2011). But the framework can also be used to develop basic statements that aim to explain designing in general instead of to distinguish between design professions. Gero and KannengiesserâĂŹs model of eight types of transformations could be used to synthesize general, basic statements about designing. For instance, one kind of transformation describes how designers transform functions based on analyses of structural behavior. With little to no revision of the language in Gero and Kannengiesser's original text, this transformation could function as a basic statement: a designâẮ́s functional requirements will transform following analyses of its structural behavior.

Figural Complexity might yield a different set of basic statements about designing. Schön theorizes designing from the perspective of the design proposal, which means that, as with the FBS framework, artifacts or concepts are at the core of his theory. If a designer changes any part of a design proposal, with its inherent figural complexity, then their appreciation of and approach towards the whole proposal changes. Schön himself has suggested that if we were to observe designers in practice, among other things we should always see designers reframing their understanding of and approach to the design situation (Schön 1990). For example, a website designer cannot change the form or behavior of a button on a website without changing their appreciation of and approach toward the whole website. Similarly, an architect designing a house cannot change the location of a window or a door without changing their appreciation of and approach toward the whole house. While these examples are profession-specific basic statements, they are special forms of a more general basic statement about designing that we can extract from Schön's theory: when designers redefine their understanding of the design situation, they will redefine their appreciation of and approach towards their designs.

Finally, we might infer different basic statements about designing from Bounded Rationality, which theorizes designing as a form of decision-making. In our summary, we described two aspects of this theory that distinguish it from the other three. The first aspect is that a designerâĂŹs understanding of the initial design problem remains unchanged throughout the process. Simon uses something called "the diet problem" in his text (Simon 1996) to illustrate imperative logic, and it is a helpful problem to illustrate this aspect of his theory. The problem is defined as designing a diet that will meet specific nutritional requirements given specific cost constraints. According to his theory, this problem will remain unchanged over the course of the design process. And the outcome of the process will be a diet that meets the requirements given the constraints. This problem could contain a basic statement about designing in terms of design problems, namely: design problems are always fully stated and known at the outset. This statement conflicts with basic statements about design problems that we might synthesize from each of the other three theories. This is important from a Popperian perspective since it illustrates one way that our other three theories clash with established theoretical knowledge about designing. C-K theory, the FBS framework, and figural complexity suggest that design problems are ambiguous and partially known to designers. We will discuss this suggestion in more depth in a subsequent section.

In this section, we have suggested that each of our four theories supports the deduction of basic statements about designing, which, we believe, are subject to refutation through empirical observation. These basic statements also forbid certain observational states. For example, C-K theory forbids designing from concept "stasis" or "contraction." The FBS framework 
forbids designing that does not include transformations of functions based on the observation and analysis of (proposed) structural behavior. Figural Complexity forbids designing from excluding types of learning whereby the designer reframes the requirements, trials, or criteria of fit. And Bounded Rationality forbids instances of designing that proceed from ambiguous or "not fully known" design requirements.

Given the scientific status we have attempted to confer upon these theories, we now must turn our attention to the notion that these theories do not "scientize" design; that is, they do not necessarily frame design as a systematic, objective, and rational process. Instead, as we will argue, they respect the integrity of designing as an approach distinct from science by framing it as a process that has no given problem, no given process, and no given solution.

\section{Design Problems, Processes, and Solutions}

The overall argument of this article is that scientific theories of designing do not necessarily frame design as a systematic, objective, and rational process. Of our four theories, Bounded Rationality skews closest to a "scientized" theory of designing. It has even been described as the culmination of the design science decade, during which many design theorists and practitioners sought to develop the design version of the scientific method (Cross 2001). So maybe Bounded Rationality does not provide an understanding of designing as an approach distinct from science whereas our other three theories do.

If the remaining three theories, C-K theory, the FBS framework, and Figural Complexity, do not scientize designing, then what kind of understanding of designing do they provide us with? We suggest that these theories provide us with an understanding of designing as having at least three distinct characteristics: designing has no given problem, no given process, and no given solution.

It is apparent that each of these three theories has concerns with some of the common terms used in the field, such as: problem, process, and solution. For instance, Hatchuel has suggested that "problem" is an ill-suited term for designing since - at least as Herbert Simon uses the term - "problem" negates the possibility of concept expansion and implies a deterministic relationship between constraints and design work (Hatchuel 2001). We agree. Moreover, as we will argue, according to our three theories, design outcomes in and of themselves do not solve problems. It would be more accurate to say that they propose or plan potentially viable solutions to problems. But proposals and plans are not solutions.

These critiques of terminology and alternative propositions seem to be more than just matter of convenience or preference. They seem to reflect a much deeper awareness of the importance of meaning. Using the terms problem, process, and solution when talking about design has consequences for our attempt to demarcate design from other approaches. We therefore do not see it simply as a measure of preference when recasting problems as "existing situations," which can be construed as problems or not. Neither is it a matter of convenience to recast solutions as "preferred situations." Developing a 'common language' of designing would certainly be interesting and useful. But in its absence, we will for the sake of simplicity discuss three distinct characteristics of designing that emerge from our analysis of these theories by using the terms problem, process, and solution. 


\subsection{Designing has no given problem}

By "no given problem" we mean that design briefs, specifications, or requirements, even if clearly stated, are only partially known at the outset and change over time as design activity occurs. On this issue, Hatchuel and Weil, Gero, and Schön all seem to be aligned. For example, Hatchuel and Weil argue that "ambiguity, ill-defined issues, and poor project wording are not problems or weaknesses in design, they are necessary" (Hatchuel and Weil 2009). And although Gero does not claim that ambiguity or poor wording are necessary per se, he does observe that designers are able to begin designing with "incomplete information" and before all relevant information is knowable. In other words, designers are able to begin designing even though the requirements are not fully known at the outset. Finally, one of Schön's critiques of Simon's theory is its failure to account for the "ill-formed problems" characteristic of the early stages of designing (Schön 1990). For Schön, it is only as designing progresses that problems mature and become well formed. However, this can only happen after a basic design structure has stabilized. Moreover, we can see how these claims inform each model of designing.

C-K theory models designing as a process of expansion, and its starting point is a nascent concept in the $\mathrm{C}$-space. Once this concept has been established, the designer moves into the K-space to prove the concept. "No given problem" can be viewed in C-K theory as a prerequisite for designing since ambiguity is apparently a driving force behind the expansion of the $\mathrm{C}$ and $\mathrm{K}$ spaces. In the same way that the first concept in $\mathrm{C}-\mathrm{K}$ theory initiates expansion, the formulation of the initial set of functional requirements in the FBS framework initiates transformations. The initial set of functional requirements is actually the output of the "formulation" step (Gero and Kannengeisser 2014) Formulation describes the move from requirements to functions. But this initial set of functions is iteratively transformed throughout the design process. Iterative transformation is perhaps analogous to the expansion occurring in C-K theory. Finally, Schön proposes the concept of generative metaphor (Boxenbaum and Rouleau 2011; Schön 1993; Thibodeau and Boroditsky 2011) as the first step in designing. Generative metaphors reframe ambiguous problems in familiar ways and in so doing they (1) map a path towards possible solutions and (2) provide more concrete ways for designers to explore these possible solutions. Generative metaphor can be interpreted as Schön's response to the innate ambiguity of design briefs, specifications, or requirements. Because these things are ambiguous, there must be some way to give direction to inquiry. It could be said that designing proceeds from ambiguity towards clarity, yet the nature of this procession seems as ambiguous as its starting point.

\subsection{Designing has no given process}

By "no given process" we mean that the design process cannot be clearly stated or known a priori or in medias res. It may seem as though each of our theories articulates "given" processes. $\mathrm{C}-\mathrm{K}$ theory models designing as a continuous interplay between the $\mathrm{C}$-space and the $\mathrm{K}$-space whereby concepts and knowledge expand until a design is decided upon. The FBS framework models designing as a series of transformations between functions, behaviours, and structures. Finally, Figural Complexity models designing as the perpetual reframing of the problem and the solution. From this perspective it may be possible to argue that these design theories do scientize design to some extent. Furthermore, some scientizing may be unavoidable when it comes to theorizing the design process. Such an argument should address the ways in which 
the invariant features of designing (according to these three theories) constitute an objective, systematic, and/or rational approach since the values of science are essential components of scientific practice. It would of course be possible to identify invariant features of designing that are not necessarily scientific. And this may be the case with these three theories. The FBS framework is not "how design happens," which means that the framework does not provide a linear, methodical process of transforming functions, behaviours, and structures. It provides an ontology for making sense of the constructs and interrelationships that constitute a design process. So perhaps we should refine our claim to the following: designing has no given, particular processes, where a particular process is a stated or known set of detailed steps taken to achieve an outcome. In contrast, it is clear that empirical science has given, particular processes. This means that scientific processes can be clearly stated or known prior to their application.

Empirical science concerns itself with modelling and predicting how the natural world works. It is important that empirical science is replicable since replicability is a factor in determining scientific truth. The scientific truth of an observation of a natural phenomenon relies on the principle of multiple access. Different scientists observing the same phenomenon using the same process should "see" the same thing. And the 'given' process they follow is precise because minor deviations from it can undermine the integrity of the observation. They should come to the same conclusion about the theory or hypothesis under examination. Importantly, conclusions to empirical scientific processes can be articulated a priori. This does not mean that there are no anomalies in science. There are. But in discussing the empirical scientific process, it seems reasonable to claim that there exists a finite list of known, possible outcomes, specifiable before observation. This is because there seems to be a causal relationship between the problem, process, and solution in empirical science. In other words, the problem determines the process. While the problem and process do not necessarily "cause" the empirical outcome in science, it seems reasonable to suggest that they cause the generation of a finite list of possible outcomes. These three theories suggest that the same cannot be true of designing because the problems, processes, and solutions are infinite and unknowable a priori and they "co-evolve" (Dorst and Cross 2001; Maher and Tang 2003; Reymen et al. 2009) throughout designing.

\subsection{Designing has no given solution}

By "no given solution" we do not mean that solutions remain ambiguous throughout designing. As Schön acknowledged, possible solutions emerge from well-formed problems in the later stages of designing after the design structure has achieved greater stability ((Schön 1990). Hatchuel and Weil echo Schön when they claim that it is impossible to define a list of possible "design candidates" since the list naturally changes over time through the acts of concept and knowledge expansion (Hatchuel and Weil 2009). Importantly, they reaffirm that this expansion happens as a result of acts of partitioning that would be unknown in the early stages of designing. Designers simply lack the knowledge at the outset of designing to infer the nature of final design candidate(s). Finally, Gero captures the nature of the design solution as an emergent quality of the process when he says, "... what is relevant [to the solution] only manifests itself as the design [process] proceeds and varies with the decisions taken" (Gero 1990)

There seems to be a nontrivial relationship between process and solution inherent in each 
theory. At some unspecified point in time during the design process, possible solutions emerge in response to an increasingly stable sense of what constitutes the problem.

However, while each theory describes a stable state wherein the problem is sufficiently well formed to allow for the emergence of proposals, candidates, or descriptions, this does not mean that the relationship between problem and solution-or for that matter process and solution-in design is deterministic as it is in science. In design, it is perhaps more apt to suggest, as Schön (1990) and others (Dorst and Cross 2001) have stated, that well-formed problems do not exist until there is a solution-a final design. Even with strict framing and fixed boundaries around a possible design space, limitless solutions might still emerge until a judgment is made about what is an appropriate design.

\section{Discussion}

In our analysis we explored the possibility that C-K theory, the FBS framework, and Figural Complexity communicate an understanding of designing as having no given problem, no given process, and no given solution. And we claimed that designing (as understood by these three theories) is distinct from science.

Science strives towards establishing clear problems, clear processes, and "definitive" solutions, which relate to each other in nontrivial ways. We suggested that there is a causal relationship between problems, processes, and solutions in science-a relationship that is absent (or at least not required) when it comes to designing. In design, (1) problems do not determine the process or the solution, (2) solutions do not require a specific process, and (3) a specific process does not inevitably lead to a particular solution. Instead, all three elements continuously influence each other, as captured by Schön's concept of figural complexity, Gero's notion of iterative transformation, and Hatchuel and Weil's description of the relationship between spaces $\mathrm{C}$ and $\mathrm{K}$. If it is reasonable to claim that designing has no given problem, no given process, and no given solution, what are some possible consequences of this claim?

The outcome of our analysis moves us a few steps closer to a possible "solution" to the problem of demarcation for design. Design is an approach that has no given problem, no given process, and no given solution. And just as Popper's solution to the problem of demarcation for science enabled him to distinguish science and scientific theories from pseudo-science, our "solution" similarly enables us to scrutinize particular processes in order to determine whether they truly are instantiations of designing. There are other potentially significant, interesting consequences for research as well.

One way researchers currently support design practitioners is through the generation of design methods and prescriptive design insights, which could be said to be designed to mitigate the potentially paralyzing effects of lacking problems and processes. C-K theory, for instance, can also be used as a method in the sense that it "prescribes" starting with a concept, generating new knowledge about that concept, and then iterating on it to develop new concepts. It is clear, however, that prescriptive insights and methods must operate at an abstract level in order to maintain the integrity of design as an approach distinct from science. While design problems can be identified during the design process, they are necessarily subject to change. They are neither given, nor are they fixed. And any method or insight that attempts to "give" or "fix" a problem undermines the integrity of designing.

Any attempt to prescribe designing would have to accord with the three characteristics we describe. Fixing a problem or prescribing a rigid process, such that neither the problem 
nor the process could/would change would "break" with the understanding of designing our theories express. Thus, there are limits to what can be prescribed. For example, prescribing a specific process based on a particular problem or based on an (anticipated) solution would not be possible since the problem, process, and solution necessarily "co-evolve" in designing. This consequence has significant implications for design research since so much research today is aimed at improving designing by producing prescriptive insights for designers.

A third possible consequence of our analysis is a reaffirmation of the importance of understanding design judgment. If it is true that problems, processes, and solutions are not given and cannot be fixed, then the question of how designers develop the capacity to make judgments regarding problems, processes, and solutions becomes crucial. To fix a problem or a process is to undermine the integrity of designing, but the decision to do so is also paradoxically essential. This is what Schön refers to when he writes of "rule governed procedures for transforming" (Schön 1990) design representations in the design process. How do designers set and modify these rules? The answer offered by design scholars is that designers do it through the application of design judgment (Cross 2001; Nelson and Stolterman 2012). We would argue that further inquiry about the nature and applications of design judgment will potentially lead to deeper and more useful insights about designing than any attempt to prescribe the process.

\section{Conclusion}

In this paper, we set out to examine one question: Can there be scientific theories of design that do not scientize design? We adopted Karl Popper's criteria for demarcating scientific theories from others: falsification, refutation, or testability. Simply put, if a theory is falsifiable-if from the theory one can deduce antithetical basic statements that refute its explanatory hypotheses-then it is scientific.

We used these criteria to analyse four seminal theories of designing: CK theory, the FBS framework, Figural Complexity, and Bounded Rationality. We concluded that these four theories of designing can be framed as scientific theories. Furthermore, we concluded that at least three of these theories do not scientize design-they do not turn design into a scientific activity through systematic, objective, rational processes. Moreover, we argued that at least three of the four theories respect the integrity of design as its own approach. CK theory, the FBS framework and Figural complexity provide us with an understanding of design as having: no given problem, no given process, and no given solution. We suggest that these theories subscribe to a common theoretical core when it comes to the nature of designing. We also suggest that our findings have concrete implications for further research about designing.

\section{References}

Boxenbaum, E. and Rouleau, L. (2011). New knowledge products as bricolage: Metaphors and scripts in organizational theory. The Academy of Management Review, 36(2):272-296.

Cascini, G., Fantoni, G., and Montagna, F. (2013). Situating needs and requirements in the FBS framework. Design Studies, 34(5):636-662.

Cavalluci, D. (2014). Designing the Inventive Way in the Innovation Era. In Chakrabarti, A. 
and Blessing, L., editors, An Anthology of Theories and Models of Design, pages 237-262. Springer, London.

Chakrabarti, A. and Blessing, L. (2014). Theories and Models of Design: A Summary of Findings. In Chakrabarti, A. and Blessing, L., editors, An Anthology of Theories and Models of Design, pages 1-45. Springer, London.

Cross, N. (2001). Designerly ways of knowing: Design discipline versus design science. Design Issues, 17(3):49-55.

Davis, M. S. (1971). That's Interesting! Philosophy of the Social Sciences, 1(2):309-344.

Dorst, K. and Cross, N. (2001). Creativity in the design process: co-evolution of problemâ̆̆Şsolution. Design Studies, 22(5):425-437.

Dubberly, H. (2018). Models.

Farrell, R. and Hooker, C. (2012). The SimonâĂŞKroes model of technical artifacts and the distinction between science and design. Design Studies, 33(5):480-495.

Galle, P. (2011). Foundational and instrumental design theory. Design Issues, 27(4):81-94.

Galle, P. and Kroes, P. (2014). Science and design: Identical twins? Design Studies, 35(3):201231.

Gero, J. S. (1990). Design prototypes: A knowledge representation schema for design. AI Magazine1, 11(4):26-36.

Gero, J. S. (1998). Conceptual designing as a sequence of situated acts. In Smith, I., editor, Artificial Intelligence in Structural Engineering, Lecture Notes in Computer Science, pages 165-177. Springer-Verlag.

Gero, J. S. and Kannengeisser, U. (2003). The situated function-behavior-structure framework. Design Studies, 25:373-391.

Gero, J. S. and Kannengeisser, U. (2014). The Function-Behaviour-Structure Ontology of Design. In Chakrabarti, A. and Blessing, L., editors, An Anthology of Theories and Models of Design, pages 263-283. Springer, London.

Godfrey-Smith, P. (2009). Theory and reality: An introduction to the philosophy of science. University of Chicago Press, Chicago, IL.

Hatchuel, A. (2001). Towards design theory and expandable rationality: The unfinished program of Herbert Simon. Journal of Management \& Governance, 5(3):260-273.

Hatchuel, A., Le Masson, P., Reich, Y., and Weil, B. (2011). A systematic approach of design theory using generativeness and robustness. In Culley, S., Hicks, B., MaAloone, T., Howard, T., and Reich, Y., editors, Proceedings of the 18th International Conference on Engineering Design (ICED 11), pages 87-97, Copenhagen, DK. The Design Society.

Hatchuel, A., Reich, Y., Masson, P. L., Weil, B., and Kazakçi, A. (2013). Beyond Models and Decisions: Situating Design through generative functions. In Proceedings of the International Conference on Engineering Design (ICED) 2013, Seoul, South Korea. The Design Society. 
Hatchuel, A. and Weil, B. (2003). A new approach to innovative design: An introduction to C-K theory. In Folkeson, A., Gralen, K., Norell, M., and Sellgren, U., editors, Proceedings of ICED 03, the 14th International Conference on Engineering Design, page Paper no. DS31_1794FPC, Stockholm.

Hatchuel, A. and Weil, B. (2009). C-K design theory: an advanced formulation. Research in Engineering Design, 19(4):181-192.

Jones, D. and Gregor, S. (2007). The anatomy of a design theory. Journal of the Association for Information Systems, 8(5).

Kan, J. W. T. and Gero, J. S. (2011). Comparing designing across different domains: An exploratory case study. In Culley, S., Hicks, B., McAloone, T., Howard, T., and Reich, Y., editors, Proceedings of the 18th International Conference on Engineering Design (ICED 11), Impacting Society through Engineering Design Methodology, pages 194-203, Copenhagen, DK.

Kim, S. H. (2017). Max Weber.

Kuhn, T. (1970). Logic of discovery or psychology of research? In Lakatos, I. and Musgrave, A., editors, Criticism and the Growth of Knoledge. Cambridge University Press, Cambridge, UK.

Lakatos, I. (1970). Falsification and the methdology of scientific research programs. In Lakatos, I. and Musgrave, A., editors, Criticism and the growth of knowledge, pages 91-196. Cambridge University Press, Cambridge, UK.

Lawson, B. and Dorst, K. (2009). Design expertise. Architectural Press.

Maher, M. and Tang, H.-H. (2003). Co-evolution as a computational and cognitive model of design. Research in Engineering Design, 14(1):47-64.

Margolin, V. (2014). World history of design.

Nelson, H. G. and Stolterman, E. (2012). The design way : intentional change in an unpredictable world. The MIT Press.

Popper, K. (2002a). Conjectures and refutations : the growth of scientific knowledge. Routledge.

Popper, K. (2002b). The logic of scientific discovery. Routledge.

Reymen, I., Dorst, K., and Smulders, F. (2009). Co-evolution in Design Practice. In Designing - Analyzing Design Meetings, pages 67-82. CRC Press, Boca Raton, FL.

Schön, D. (1990). The Design Process. In Howard, V., editor, Varieties of Thinking: Essays from Harvard's Philosophy of Education Research Center, pages 110-141. Philosophy of Education Research Library, New York and London.

Schön, D. A. (1983). The reflective practitioner : how professionals think in action. Basic Books. 
Schön, D. A. (1993). Generative metaphor: A perspective on problem-setting in social policy. In Ortony, A., editor, Metaphor and Thought, pages 137-163. Cambridge University Press, Cambridge.

Simon, H. A. (1996). The sciences of the artificial. MIT Press.

Taura, T. (2014). Motive of Design: Roles of Pre- and Post-design in Highly Advanced Products. In An Anthology of Theories and Models of Design, pages 83-98. Springer London, London.

Thibodeau, P. H. and Boroditsky, L. (2011). Metaphors We Think With: The Role of Metaphor in Reasoning. PLoS ONE, 6(2):e16782.

Vermaas, P. E. and Dorst, K. (2007). On the conceptual framework of John Gero's FBS-model and the prescriptive aims of design methodology. Design Studies, 28(2):133-157.

Weick, K. E. (1989). Theory Construction as Disciplined Imagination. The Academy of Management Review, 14(4):516.

Xenakis, I. and Arnellos, A. (2013). The relation between interaction aesthetics and affordances. Design Studies, 34(1):57-73.

Ziman, J. (2000). Real Science. Cambridge University Press, Cambridge.

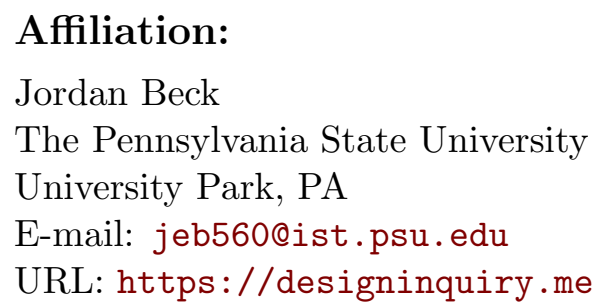

SocArXiv Website SocArXiv Preprints

Preprint

10.31219/osf.io/dz9xr https://socopen.org/ https://osf.io/preprints/socarxiv

Submitted: November 5, 2018 Accepted: November 5, 2018 